\title{
OBSERVASI PERTUMBUHAN AWAN DI DAS MAMASA SULAWESI BARAT DENGAN RADAR CUACA
}

\author{
Erwin Mulyana
}

\begin{abstract}
Study on the characteristic of cloud development at Mamasa catchment area is very important since the water supply for Bakaru hydro-electric power is highly depend on the rain fall over this area. During rain enhancement project on 21 October to 19 November 2009, convective clouds have been analized based on X-band mobile weather radar observation over Mamasa River catchment area. The observation result shows that cloud development in this area are influenced by orographic processes and wind direction. During westerly wind, the clouds developed over the western part of catchment area. On the contrary, the clouds were observed over the east side of cathment area during easterly wind.
\end{abstract}

\section{Intisari}

Telah dilakukan pengamatan awan di DAS Mamasa berdasarkan data X-band Mobile Radar untuk mengetahui karakteristik pertumbuhan awan di daerah tersebut. Pengamatan awan dilakukan pada saat kegiatan penyemaian awan tangal 21 Oktober 19 November 2009. Hasil pengamatan menunjukkan bahwa pertumbuhan awan di DAS Mamasa dipengaruhi oleh proses orografik dan arah angin. Pada saat angin baratan, pertumbuhan awan terkonsentrasi di sisi bagian barat DAS Mamasa. Sebaliknya, pertumbuhan awan terkonsentrasi di sisi bagian timur DAS Mamasa ketika terjadi angin timuran.

Kata kunci : Pertumbuhan awan, radar cuaca, proses orografik, arah angin, DAS Mamasa.

\section{PENDAHULUAN}

Terdapat tiga faktor utama yang mempengaruhi variabilitas iklim di Sulawesi khususnya di Sulawesi Tengah (Gunawan, 2006). Tiga faktor tersebut adalah El Nino Southern Oscillation (ENSO), Monsun Asia-Australia dan faktor lokal yang sangat bergantung pada karakteristik topografi masing masing daerah. Aldrian, (2002) menyebutkan pola hujan di Sulawesi sebelah selatan ekuator dipengaruhi oleh system sirkulasi monsoon. Pola monsunal ini ditandai oleh perbedaan yang sangat tegas yaitu musim kemarau yang berkaitan dengan monsun Australia dan musim hujan yang berkaitan dengan monsun Asia.

Akhir-akhir ini semakin sering terjadi ketidak teraturan musim antara musim hujan dan musim kemarau. Kemarau panjang berdampak terhadap kurangnya sumber air di beberapa Pusat Listrik Tenaga Air. Hal ini mengakibatkan berkurangnya

\footnotetext{
${ }^{1}$ Peneliti Madya - UPT Hujan Buatan, BPPT, Thamrin No. 8 Jakarta, email: erwin6715@yahoo.com
}

pasokan listrik untuk masyarakat. Salah satu PLTA yang mengalami krisis air adalah PLTA Bakaru yang memanfaatkan aliran sungai Mamasa.

Upaya menambah curah hujan untuk meningkatkan pasokan air di PLTA Bakaru telah dilakukan dengan cara penyemaian awan di Daerah Aliran Sungai (DAS) Mamasa. Untuk mendapatkan awan potensial di DAS Mamasa yang layak disemai maka dilakukan observasi awan dengan menggunakan radar cuaca. Radar cuaca diantaranya dapat memberikan informasi ketingian dasar, puncak, serta arah pergerakan awan.

Beberapa penelitian tentang faktor-faktor yang mempengaruhi pertumbuhan awan di wilayah Indonesia telah banyak dilakukan. Hadi dkk $(2000,2002)$ menyebutkan pengaruh angin laut terhadap pertumbuhan awan di wilayah Jakarta. Variasi tahunan dan harian dari awan telah diteliti oleh Renggono dkk (2011). Sedangkan aktifitas konveksi di wilayah Indonesia dipengaruhi intra seasonal variation (Seto, 2004, 2006).

Pada tulisan ini akan dibahas karakteristik pertumbuhan awan di DAS Mamasa pada saat kegiatan pelaksanaan penyemaian awan untuk 
menambah curah hujan di DAS Mamasa bagi keperluan PLTA Bakaru.

\section{METODOLOGI}

Metodologi yang digunakan dalam kegiatan ini adalah dengan melakukan observasi langsung menggunakan radar cuaca untuk melihat sebaran awan secara spasial dan temporal. Pengamatan dilakukan pada tanggal 21 Oktober sampai dengan 19 Nopember 2009.

Untuk melihat faktor regional dan global yang mempengaruhi cuaca lokal digunakan informasi suhu permukaan laut dari NOAA dan dan angin gradient dari Bureau of Meteorology Australia.

\subsection{Daerah Penelitian}

Penelitian dilakukan di DAS Mamasa yang berada di dua provinsi, yaitu Provinsi Sulawesi Barat yang merupakan bagian hulu DAS Mamasa dan Provinsi Sulawesi Selatan yang merupakan bagian hilir DAS Mamasa.

Daerah Aliran Sungai merupakan suatu kawasan yang dibatasi oleh pemisah topografi yang menampung, menyimpan dan mengalirkan curah hujan yang jatuh di atasnya ke dalam suatu system pengaliran sungai yang mengalir dari hulu menuju hilir sungai atau tempat tertentu. Bentuk DAS Mamasa memanjang dari utara ke selatan seperti diperlihatkan pada Gambar 1.

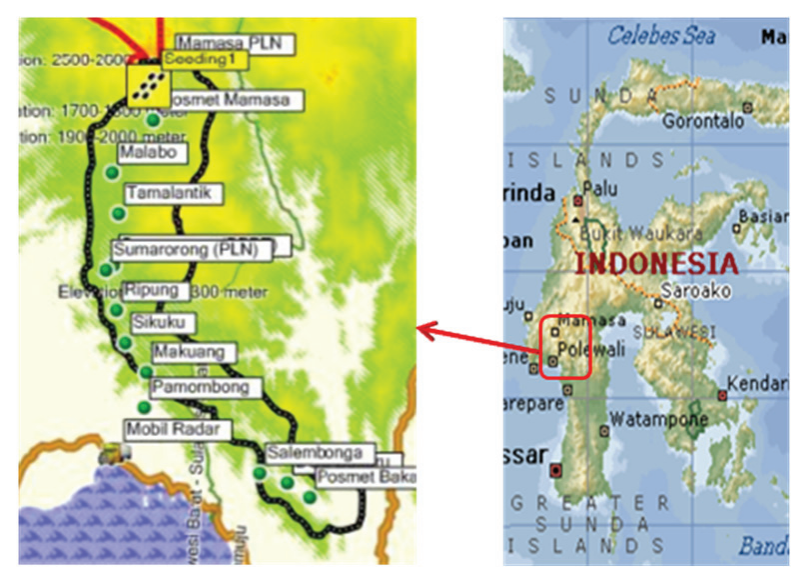

Gambar 1. Daerah Aliran Sungai Mamasa yang ditandai oleh garis hitam tebal.

Secara geografis daerah aliran Sungai Mamasa meliputi Kabupaten Mamasa dan Kabupaten Polewali Mandar di Sulawesi Barat serta Kabupaten Pinrang dan Kabupaten Enrekang di Sulawesi Selatan. Luas DAS Mamasa kurang lebih 118.500 hektar. Hulu Sungai Mamasa berada di Kabupaten Mamasa, kemudian mengalir ke arah selatan dan berakhir di Kabupaten Pinrang.

\subsection{Data yang digunakan}

Data yang digunakan dalam penelitian ini adalah data primer berupa citra awan hasil observasi dengan radar cuaca. Radar cuaca yang digunakan adalah $\mathrm{X}$ band mobile weather radar milik UPT Hujan Buatan, Badan Pengkajian dan Penerapan Teknologi. Radar ini mampu mendeteksi awan hingga radius $150 \mathrm{~km}$. Mobile radar ditempatkan di Polewali pada koordinat 119018' BT dan 3025' LS.

Mobile radar yang digunakan dalam pengamatan ini ditunjukkan pada Gambar 2, sedangkan spesifikasi teknisnya dapat dilihat pada Tabel 1.

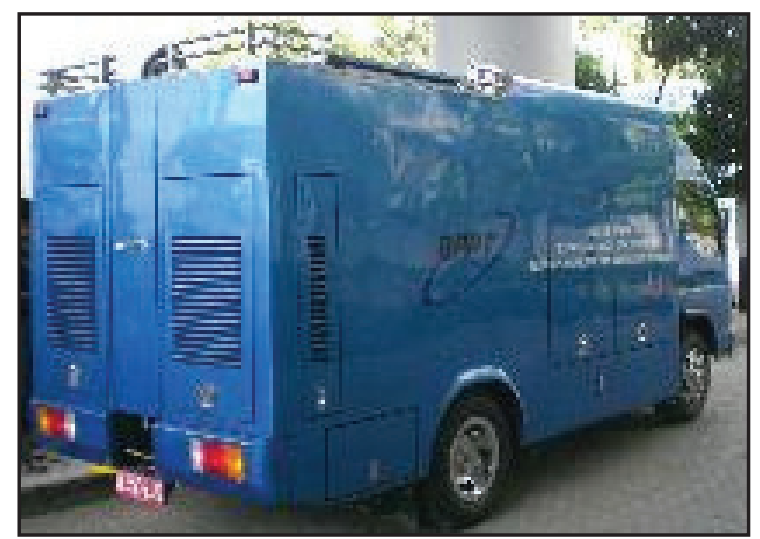

Gambar 2. Mobile Weather Radar yang digunakan untuk observasi awan

Tabel 1. Spesifikasi teknis Mobile Weather Radar

\begin{tabular}{|c|l|}
\hline Antenna & $\begin{array}{l}\text { Slotted Array Flat Plate, } \\
\text { Lightweight Aluminum or Parabolic } \\
\text { Dish }\end{array}$ \\
\hline Beam Width & $\begin{array}{l}3.6 \text { Degrees, }\left(2.2^{\circ}-4^{\prime} \text { and } 1.1^{\circ}-\right. \\
\left.6^{\prime}\right)\end{array}$ \\
\hline $\begin{array}{c}\text { Tilt (vertical } \\
\text { scan) }\end{array}$ & through + 90 Degrees \\
\hline Azimuth & $\begin{array}{l}360 \text { Degree Rotation Plus User } \\
\text { Specified Sector Scanning }\end{array}$ \\
\hline Transmit & $\begin{array}{l}\text { 200 Watts Minimum } \\
\text { Fully Coherent on Transmit with } \\
\text { Pulse Compression (equivalent to } \\
12,620 \text { watts) } \\
\text { Prequency 9.345GHz, User } \\
\text { Tunable Within }+/-25 \text { MHz }\end{array}$ \\
\hline Workstation/ & $\begin{array}{l}\text { Pentium IV Laptop or Desktop, } \\
\text { Windows XP Operating System } \\
\text { EWR Weather ScoutTM and } \\
\text { Sigmet IrisTM Software Packages }\end{array}$ \\
\hline Operating & $\begin{array}{l}\text { X Band, 9.345 GHz, User Tunable } \\
\text { Within +/-25 MHz }\end{array}$ \\
\hline Frequency & $\begin{array}{l}\text { Sigmet RVP8 as used in the } \\
\text { NEXRAD System }\end{array}$ \\
\hline Signal \\
Processor \\
\hline Range & $\begin{array}{l}\text { 150 km (max theoretical limited by } \\
\text { earth's curvature) }\end{array}$ \\
\hline
\end{tabular}

\section{HASIL DAN PEMBAHASAN}

\subsection{Kondisi Global dan Regional}

Kondisi cuaca di DAS Mamasa pada saat 
dilakukan penelitian dipengaruhi oleh fenomena El Nino yang ditandai dengan anomaly positif suhu permukaan laut di Samudera Fasifik ekuator (lihat Gambar 3).

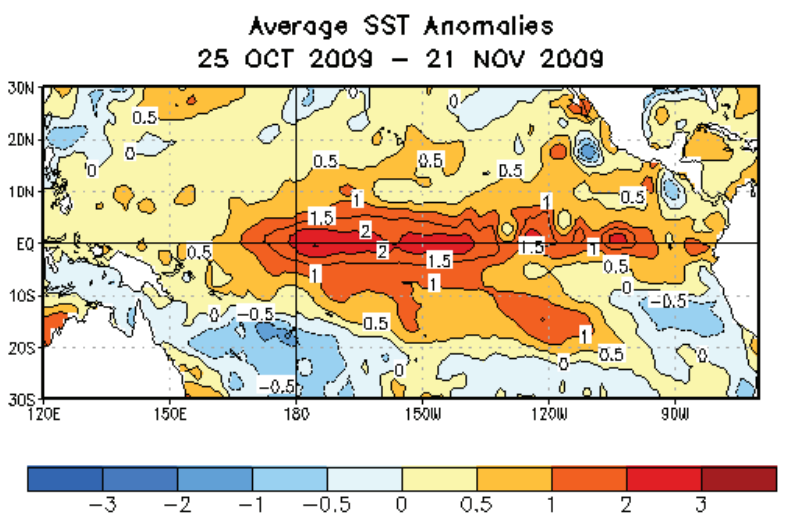

Gambar 3. Rata-rata anomaly suhu permukaan laut di Samudra Pasifik yang menunjukkan sedang berlangsungnya El Nino (sumber :NOAA)

Berdasarkan penjalaran MJO terlihat bahwa pada dasarian ketiga bulan Oktober 2009 wilayah Indonesia masuk pada fase kering seperti ditunjukkan pada Gambar 4. Kondisi demikian mengakibatkan keringnya kondisi atmosfer di sebagian besar wilayah Indonesia, Kondisi cuaca di daerah penelitian juga terpengaruh oleh munculnya siklon tropis Mirinae di sekitar perairan Filipina. Siklon ini menarik masa udara ke pusat siklon sehingga mengganggu pertumbuhan awan di DAS Mamasa.

\subsection{Observasi Radar}

Hasil observasi radar cuaca menunjukkan bahwa pertumbuhan awan yang di DAS Mamasa mulai terjadi pada siang hingga sore hari. Faktor lokal seperti angin laut cukup berpengaruh terhadap pertumbuhan awan di daerah tersebut.

Angin laut dari arah selatan yang berhembus pada pagi hingga siang hari mengakibatkan uap air naik ke atmosfer akibat tertahan oleh pegunungan yang ada di sekitar DAS Mamasa. Uap air tersebut akhirnya membentuk awan orografik di sebagian besar batas DAS bagian barat dan bagian selatan seperti di daerah Sumarorong dan Makuang. Beberapa penelitian menunjukkan bahwa angin laut dapat mencapai daratan hingga 60- 80 km (Hadi, 2000,2002).

Secara umum keberadaan awan potensial yang berada di DAS Mamasa berfluktuasi. Pada 3 hari pertama kegiatan, awan potensial cukup banyak ditemui di dalam DAS. Kondisi atmosfer selanjutnya berangsur-angsur menjadi kering

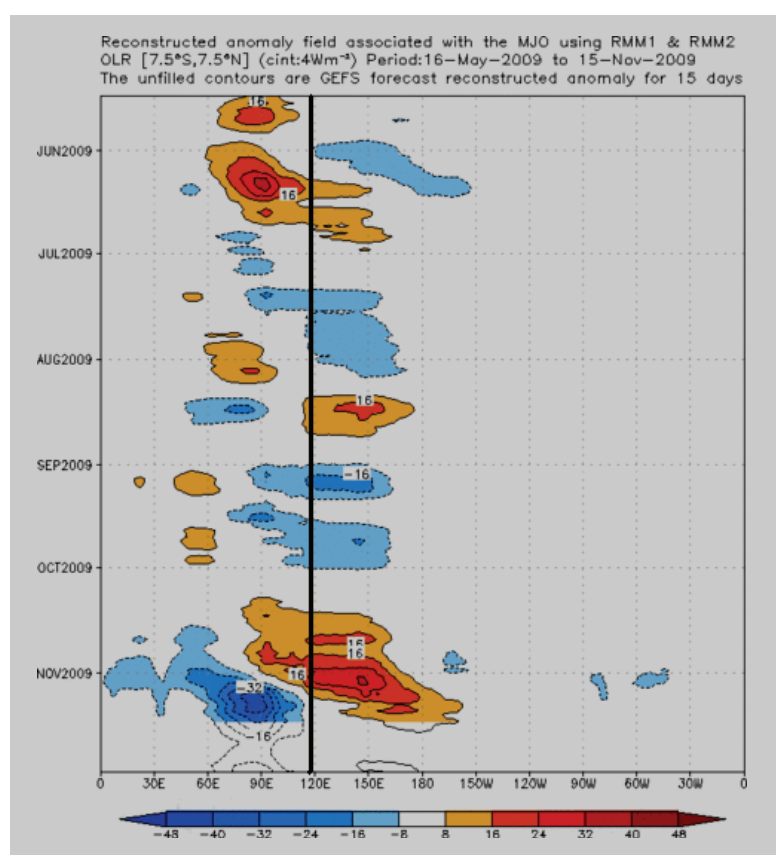

Gambar 4. Penjalaran MJO mulai Juni hingga pertengahan Nopember 2009. Garis vertical tebal merupakan garis bujur DAS Mamasa.

sehingga awan di daerah target dan sekitarnya sulit terbentuk. Kondisi kering tersebut berlangsung hingga akhir bulan Oktober, kecuali pada tanggal 27, 30 dan 31 Oktober.

Gambar 5 menunjukkan contoh kondisi atmosfer kering pada tanggal 26 Oktober 2009. Dari gambar tersebut tampak beberapa sel awan di sebelah sebelah barat Mamasa, sedangkan di dalam DAS Mamasa tidak tampak adanya

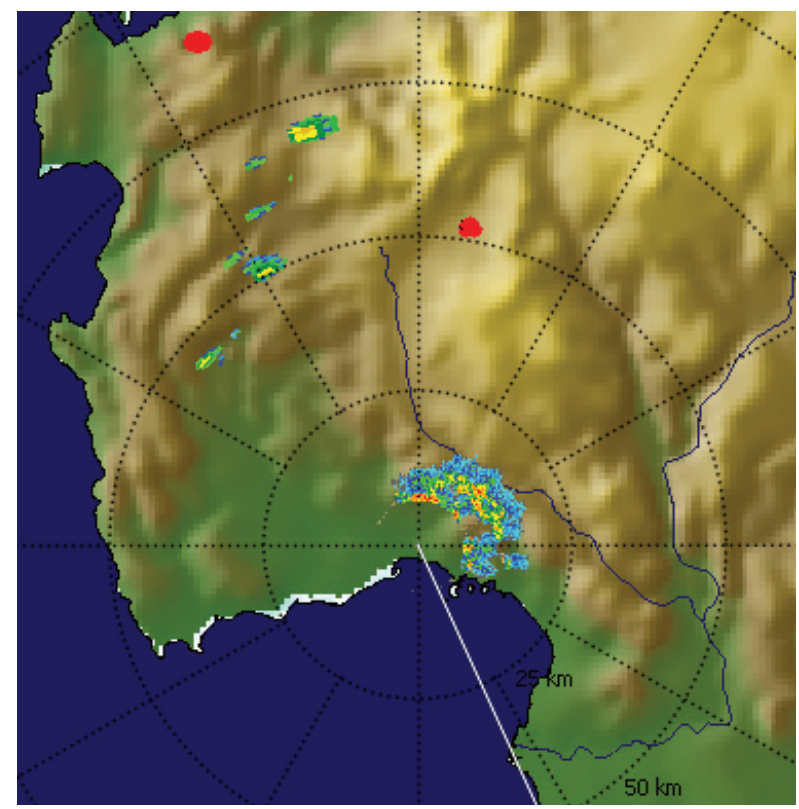

Gambar 5. Pantauan radar cuaca pada tanggal 26 Oktober 2009 jam 14.15 WITA yang menunjukkan kondisi atmosfer kering. Di DAS Mamasa tidak tampak adanya awan yang termonitor oleh radar cuaca. 


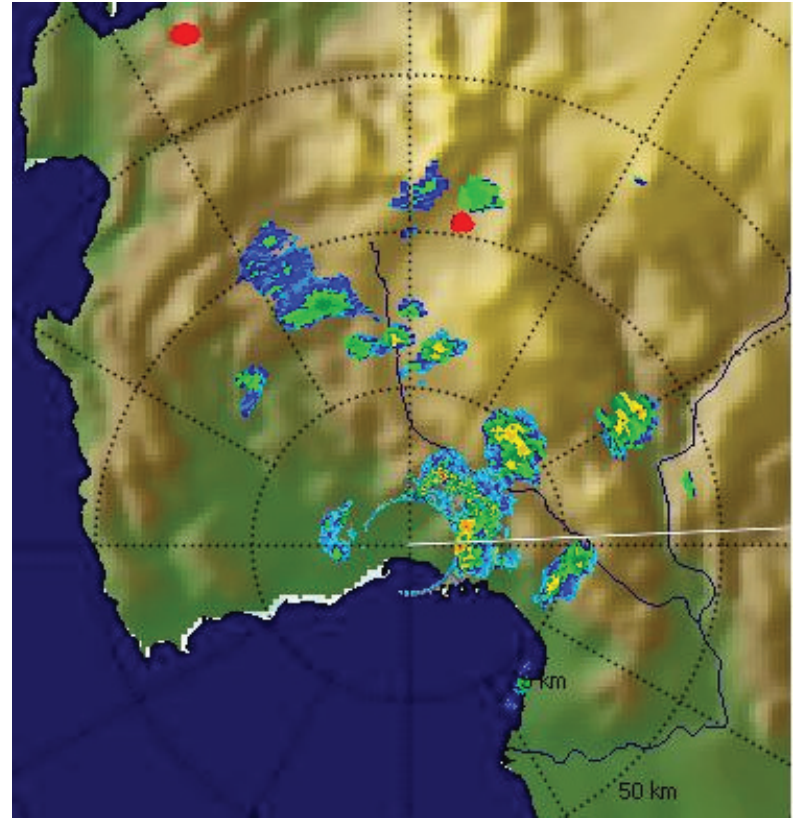

Gambar 6. Citra radar cuaca pada tanggal 07 Nopember 2009 jam 15.15 WITA yang menunjukkan kondisi atmosfer basah. Tampak awan banyak ditemukan di dalam maupun di luar DAS Mamasa.

pertumbuhan awan. Daerah yang dilingkari warna putih (arah utara-timur radar) bukan merupakan awan akan tetapi noise (ground cluter) oleh pebukitan yang ada di sekitar lokasi radar.

Masuk bulan Nopember hingga pertengahan bulan Nopember, kondisi atmosfer kembali lembab sehingga awan banyak ditemui di dalam DAS maupun di daerah sekitarnya. Selama kurun waktu tersebut hanya ditemukan kondisi atmosfer kering pada tanggal 3, 5, 10 dan 14 Nopember 2009.

Gambar 6 merupakan contoh kondisi atmosfer basah pada tanggal 7 Nopember 2009. Sejumlah sel awan tampak di dalam maupun di luar DAS Mamasa.

Selanjutnya pertumbuhan awan yang berada di DAS Mamasa berfluktuasi. Pada tanggal 19 Nopember, atmosfer cukup lembab sehingga awan potensial banyak tumbuh di dalam DAS. Atmosfer kemudian berubah menjadi kering, akibatnya pertumbuhan awan sulit terbentuk. Kondisi kering tersebut berlangsung selama 2 hari yaitu tanggal 20 dan 21 Nopember (lihat Gambar 7).

Menuju akhir bulan Nopember, Kondisi atmosfer kemudian berubah lagi menjadi lembab sehingga mudah terjadi pembentukan awan di dalam DAS. Kondisi atmosfer lembab tersebut terus bertahan hingga kegiatan observasi berakhir pada tanggal 29 Nopember 2009. Pada periode ini awan banyak tumbuh di sisi batas DAS bagian barat hingga sisi batas DAS bagian selatan (lihat Gambar 8).

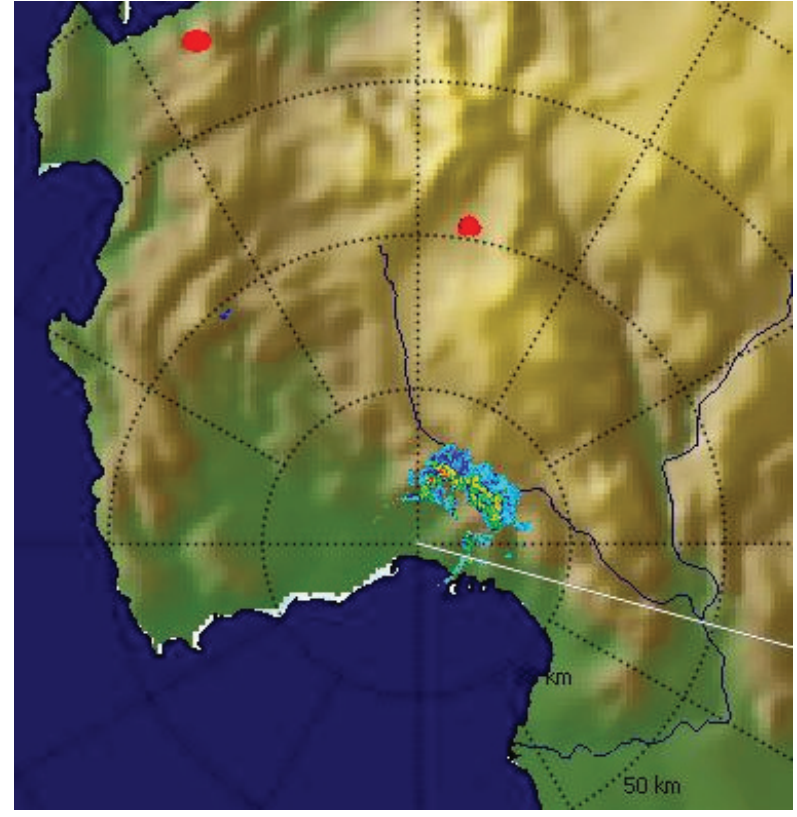

Gambar 7. Citra radar cuaca pada tanggal 21 Nopember 2009 jam 14.15 WITA yang menunjukkan kondisi atmosfer kering. Di DAS Mamasa tidak tampak adanya awan yang termonitor oleh radar cuaca.

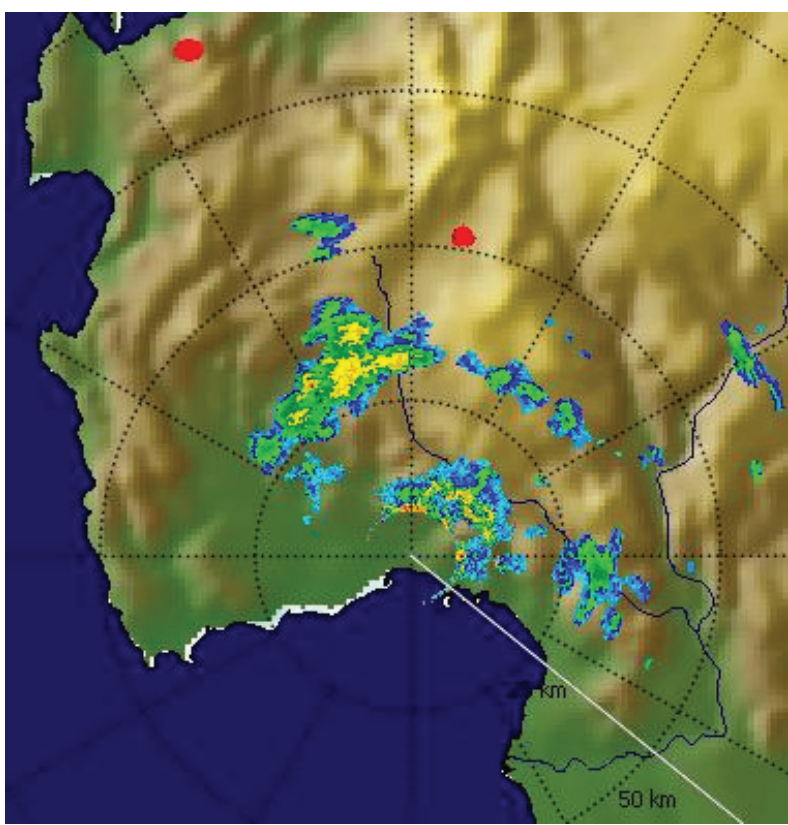

Gambar 8. Citra radar cuaca yang menunjukkan kondisi atmosfer basah pada tanggal 25 Nopember 2009 jam 14.50 WITA. Tampak awan potensial berada di dalam maupun di luar DAS Mamasa.

Analisis spasial menunjukkan adanya keterkaitan antara arah angin dengan lokasi pertumbuhan awan di DAS Mamasa. Pada saat angin baratan berlangsung, pertumbuhan awan di DAS Mamasa dominan berada di sisi sebelah barat DAS. Hal ini mengindikasikan adanya pertumbuhan 
awan akibat proses orografik. Uap air yang datang dari arah barat dipaksa naik oleh pebukitan di sisi barat DAS sehingga terbentuk awan di daerah tersebut. Proses inilah yang menyebabkan daerah Sumarorong paling sering pertumbuhan awannya. Kondisi ini bersesuaian dengan banyaknya hujan di daerah Sumarorong (Muchtar, 2006). Kondisi sebaliknya ditemui pada saat belangsung angin timuran, dimana pertumbuhan awan banyak ditemukan di bagian timur batas DAS Mamasa.

\section{KESIMPULAN DAN SARAN}

Berdasarkan hasil observasi awan dengan radar cuaca di DAS Mamasa dapat diambil beberapa kesimpulan yaitu :

1. Pertumbuhan awan di DAS Mamasa sangat dipengaruhi oleh proses orografis berupa adanya pengangkatan uap air oleh pebukitan di sepanjang batas DAS Mamasa.

2. Arah angin sangat berpengaruh terhadap penyebaran lokasi awan. Ketika berlangsung angin baratan, awan banyak tumbuh di sisi sebelah barat DAS. Sebaliknya ketika berlangsung angin timuran, awan banyak tumbuh di sisi sebelah timur batas DAS.

3. Daerah Sumarorong merupakan daerah yang paling sering pertumbuhan awannya dibandingkan dengan daerah lainnya yang berada di dalam DAS.

Diperlukan penelitian lanjutan untuk lebih mengetahui karakteristik awan orografik di daerah tersebut.

\section{DAFTAR PUSTAKA}

Aldrian. E, 2002: Spatial Patterns of ENSO Impact on Indonesia Rainfall, Jurnal Sains \& Teknologi Modifikasi Cuaca, Vol. 3, no.1, 5-9
Gunawan, D., 2006: Atmospheric Variability in Sulawesi, Indonesia Regional Atmospheric Model Result and Observation Desertasi, Georg August Universitat Gottingen.

Hadi, T. W., T. Tsuda, H. Hashiguchi, and S. Fukao, 2000: Tropical Sea-breeze Circulation and Related Atmospheric Phenomena Observed with L-band Boundary Layer Radar in Indonesia, J. Meteor. Soc. Japan, Vol. 78, No. 2, pp. 123-140.

Hadi. Tri W., T. Horinouchi, T.Tsuda, H.Hashiguchi and S.Fukao, 2002 : Sea-Breeze Circulation over Jakarta, Indonesia: A Climatology Based on Boundary Layer Radar Observation. Mon.Wea.Rev., 130 (9), 2153-2166.

Muchtar. A, 2006: Analisis factor faktor yang mempengaruhi debit Sungai Mamasa Sulawesi selatan. J. Sain \& Teknologi, Vol. 6, No.1 : 41-58.

Renggono, F, Hiroyuki Hashiguchi, Shoichiro Fukao, Manabu D Yamanaka, Shinya Ogino, Noriko Okamoto, Fumie Murata, Sriworo B Harijono, Mahally Kudsy, Mahdi Kartasasmita, Sri Diharto, 2001: Precipitating clouds observed by $1.3 \mathrm{GHz}$ boundary layer radars in equatorial Indonesia, Ann. Geophys., 19, 889-897.

Seto, T.H., M. K. Yamamoto, H. Hashiguchi, and S. Fukao, 2004: Convective activities associated with intraseasonal variations over Sumatera, Indonesia, observed with the equatorial atmosphere radar, Ann Geophys, 22, pp 3899-3916.

Seto, T. H., M. K. Yamamoto, H. Hashiguchi, S. Fukao, M. Abo., T. Kozu., M. Kudsy, 2006: Observational Study on Westerly Wind Burst over Sumatra, Indonesia by the Equatorial Atmosphere Radar - A Case Study During the First CPEA Campaign -, J. Meteor. Soc. Japan, 84A, pp 95-112. 
